\title{
Characteristics Analysis of Segmental and Regional Lumbar Spontaneous Compensation Post Selective Thoracic Fusion in Lenke 1 and 2 Adolescent Idiopathic Scoliosis
}

Kai Chen

Shanghai Changhai Hospital

Xiao Zhai

Shanghai Changhai Hospital

Tianjunke Zhou

Basic medicine college, Navy Medical University

Yu Deng

Shanghai Changhai Hopital

Shaofeng Chen

Shanghai Changhai Hospital

Changwei Yang

Shanghai Changhai Hospital

Ming Li ( $\nabla$ limingch0103@126.com)

Shanghai Changhai Hospital

\section{Research Article}

Keywords: selective thoracic fusion, AIS, spontaneous compensation, characteristics, unfused lumbar segments.

Posted Date: July 9th, 2021

DOl: https://doi.org/10.21203/rs.3.rs-677352/v1

License: (c) (i) This work is licensed under a Creative Commons Attribution 4.0 International License. Read Full License 


\section{Abstract}

Objective To explore the characteristics of compensation of unfused lumbar region post selective thoracic fusion in Lenke 1 and 2 adolescent idiopathic scoliosis

Method A total of 51 Lenke 1 and2 AIS patients were included, whose lowest instrumented vertebrae was L1 from January 2013 to December 2019. For further analysis, demographic data and coronal radiographic films were collected before surgery, at immediate erect postoperatively and final follow-up. The wedge angles of each unfused distal lumbar segments were measured, and the variations in each disc segment were calculated at the immediate postoperative review and final follow-up. Meanwhile, the unfused lumbar curve was divided into upper and lower parts, and calculated their curve angles and compensations.

Results The current study enrolled 41 females (80.4\%) and 10 males (19.6\%). 36 patients were Lenke type 1 , while 15 patients were Lenke type 2 . The average main thoracic Cobb angle and thoracolumbar/lumbar Cobb angle were $44.1 \pm 7.7^{\circ}$ and $24.1 \pm 9.3^{\circ}$, preoperatively. At the final follow-up, the disc wedge angle variation of $L 1 / 2, L 2 / 3, L 3 / 4, L 4 / 5$ and $L 5 / S 1$ was $3.84 \pm 5.96^{\circ}, 3.09 \pm 4.54^{\circ}, 2.30 \pm 4.53^{\circ},-0.12 \pm 3.89^{\circ}$ and $-1.36 \pm 2.80^{\circ}$, respectively. The compensation of upper and lower coronal lumbar curves at final follow-up were $9.22 \pm 10.39^{\circ}$ and $-1.49 \pm 5.14^{\circ}$, respectively.

Conclusion When choosing L1 as the lowest instrumented vertebrae, the distal unfused lumbar segments' compensation showed a decreasing trend from the proximal end to the distal end. The adjacent L1/2 and L2/3 discs significantly contributed to this compensation.

\section{Background}

Lenke 1 and 2 adolescent idiopathic scoliosis (AIS) accounts for most AIS, but the optimal therapeutic approach for these patients remains controversial( $D \& A O, 2016)$. As posterior selective thoracic fusion (STF) has become the standard surgical treatment of choice(LG, 2007), numerous studies have shown that proper STF can accomplish the underlying aim of preventing scoliosis progression while maintaining global balance(Betz, 2016; J. H et al., 2018; M, M, \& M, 2019; MK et al., 2018; P. S \& JM, 2019; Skaggs et al., 2016). In addition, the spontaneous lumbar curve correction (SLCC) can be achieved by correcting the main thoracic curve. In spinal fusion, it is believed that preserving lumbar mobility is advantageous in controlling pain and maintaining its functions. However, when planning the surgical treatments, more attention should be paid to the patients' unfused lumbar curve compensation ability due to its importance to the coronal balance. Otherwise, the compensation characteristics of the spontaneous distal lumbar curve remain unclear even though it has been mentioned in some articles.

Bachmann et al. (Bachmann et al., 2020) validated that STF mainly produced changes in the upper half of the lumbar curve, leaving the lower half and the lumbosacral takeoff angle with little change. Mason et al. (DE \& $P, 1991$ ) proposed that most lumbar coronal corrections could occur in the proximal region above the lumbar apex post STF. They explained that the proximal lumbar coronal curve could be more significantly corrected than the distal lumbar area because the proximal lumbar curve would become more lordotic in the sagittal plane immediately after surgery (KH, J, KY, \& NY, 2007). Meanwhile, with a more distal lowest 
instrumented vertebrae (LIV), there is increased disc pressure and segmental motion at the adjacent level, followed by an overall reduction in lumbar activity and an increased risk of disc degeneration. Meric et al. (Enercan et al., 2015) conducted a retrospective study of AIS patients who received STF treatment, with at least ten years follow-up demonstrated a moderate rise in disc degeneration in the unfused segments. Facet joint degeneration was significant at the upper two levels adjacent to the lowest instrumented vertebra.

Although the spontaneous correction of the distal unfused lumbar curve after STF has been widely reported(Chang, Chang, \& Wu, 2007; D \& AO, 2016; K. H, W, MC, \& PO, 2019; Koller et al., 2014; Lenke et al., 1999; U. M et al., 2019; Sudo et al., 2016; TR et al., 2001; U, H, \& V, 2013); however, the impact of the spontaneous realignment of unfused segments on disc compensation remains to be quantified. To obtain an optimal balance outcome and prevent radiographical complications, such as the adding-on phenomenon, research has been conducted regarding the optimal LIV selection(MA \& DM, 2011; Skaggs et al., 2016), prediction of SLCC(K. H et al., 2019; Koller et al., 2014; U. M et al., 2019) and related long-term outcome(MK et al., 2018; Nohara et al., 2015). However, all these studies regarded the unfused distal segments as an ensemble. Till, no further research has been reported on the impact of segmental or regional disc variation. Our study focused on the distribution of distal unfused lumbar disc variation and explored the characteristics of compensation of unfused lumbar region post selective thoracic fusion in Lenke 1 and 2 adolescent idiopathic scoliosis.

\section{Methods}

\section{Patients populations}

A total of 51 consecutive patients were enrolled in this study between January 2013 and December 2019 met the inclusion and exclusion criteria. The inclusion criteria were: 1 ). $10 \leq$ Age $\leq 18$ years old; 2 ). According to Lenke classification, patients were diagnosed with Lenke 1 and 2 AIS and received a one-stage posterior correction surgery with pedicle screw; 3). LIV was L1 vertebrae; 4). The total follow-up time exceeded 24 months. The exclusion criteria were: 1). Other types of AIS or spine deformity; 2). LIV was above or below L1 vertebrae. In addition, patients without adequate radiological materials were also excluded. This current study was approved by the institutional review board of our hospital, and the patients in our study provided written informed consent for the study.

\section{Data collection}

The demographic data, including age, gender, height, weight, BMI and Lenke type were recorded. Surgeryrelated information was recorded, such as UIV (upper instrumented vertebrae), fusion segments, and pedicle screws. All patients provided full spine standing posterior-anterior X-ray before surgery, at the immediate postoperative follow-up and final follow-up. The Risser sign was calculated according to the preoperative pelvic X-ray. Other radiographic parameters were measured, such as proximal thoracic Cobb angles, main thoracic Cobb angles, thoracolumbar/lumbar Cobb angles, translation of thoracic apex (TAVT, the distance between the apex vertebra of the main thoracic curve and the cervical 7 vertebrae plumb line (C7PL)), translation of thoracolumbar/lumbar apex (LAVT, the distance between the apex vertebra of the thoracolumbar/lumbar curve and the center sacral vertical line (CSVL)) and coronal balance (the horizontal 
distance between the CSVL drawn from C7PL). The disc wedge angle was measured as the angle between the lines along the inferior endplate of the upper and the superior endplate of the lower vertebra in a segment, $\mathrm{L} 1 / 2, \mathrm{~L} 2 / 3, \mathrm{~L} 3 / 4, \mathrm{~L} 4 / 5$ and L5/S1 disc were measured, respectively (Fig 1). Each segment's variation of disc wedge angle was calculated at immediate postoperative follow-up and final follow-up reviews. As for the analysis of integral distal lumbar compensation, upper coronal lumbar curve (the Cobb angle between L1 and L4) and lower coronal lumbar curve (the Cobb angle between L4 and S1) were measured, and their compensation ability was also calculated at each follow-up. Radiographic parameters were measured by two experienced attending doctors of spine deformity, and the average value was adopted for further analysis.

\section{Statistical analysis}

Statistical analysis was performed using SPSS 19.0 statistics software (SPSS Inc, Chicago, IL). Descriptive statistics were presented in the form of mean \pm standard deviation (SD). ANOVA analysis was used to assess the quantitative data among different periods, and the SNK method was used for pairwise comparison. Pair t-test analysis was utilized to assess the compensation ability of the upper and lower coronal lumbar curve. Correlation analysis was also adopted to clarify the composition and compensation ability of each segment in the whole unfused lumbar region. $\mathrm{P}<0.05$ was considered statistical significance.

\section{Results}

A total of 51 Lenke 1 and 2 patients were enrolled in our study, including 41 females (80.4\%) and 10 males (19.6\%). 36 patients were Lenke type 1, while 15 patients were Lenke type 2 . The mean age at the time of surgery was $14.12 \pm 2.05$ years. The average preoperative height was $159.33 \pm 6.85 \mathrm{~cm}$, and the average preoperative weight was $47.27 \pm 6.69 \mathrm{~kg}$. The average BMI was $18.42 \pm 2.02 \mathrm{~kg} / \mathrm{m}^{2}$. Among the patients, the number of UIV on T1, T2, T3, T4 and T5 was 4, 9, 19, 16 and 3, respectively. The average fusion segments were $10.90 \pm 1.02$, and the mean number of instrumented pedicle screws was $15.08 \pm 2.03$. Table 1 enlisted the demographic and clinical characteristics. 
Table 1

Demographic characteristics of all subjects.

\begin{tabular}{|ll|}
\hline Variables & Cases $(\mathbf{n}=\mathbf{5 1})$ \\
\hline Gender $($ female/male) & $41 / 10$ \\
\hline Age $(\mathrm{y})$ & $14.12 \pm 2.05$ \\
\hline Risser sign $(0 / 1 / 2 / 3 / 4 / 5)$ & $9 / 4 / 8 / 7 / 16 / 7$ \\
\hline Height $(\mathrm{cm})$ & $159.33 \pm 6.85$ \\
\hline Weight $(\mathrm{kg})$ & $47.27 \pm 6.69$ \\
\hline BMI $\left(\mathrm{kg} / \mathrm{m}^{2}\right)$ & $18.42 \pm 2.02$ \\
\hline Lenke type (1\&2) & $36 / 15$ \\
\hline UIV $(T 1 / T 2 / T 3 / T 4 / T 5)$ & $4 / 9 / 19 / 16 / 3$ \\
\hline Fusion segments $(\mathrm{n})$ & $10.90 \pm 1.02$ \\
\hline Pedicle screw $(\mathrm{n})$ & $15.08 \pm 2.03$ \\
\hline
\end{tabular}

Radiographic parameters were shown in Table 2. The average main thoracic Cobb angle was $44.1 \pm 7.7^{\circ}$, the mean thoracolumbar/lumbar Cobb angle was $24.1 \pm 9.3^{\circ}$, and the mean coronal balance (C7PL-CSVL) was $11.2 \pm 7.9 \mathrm{~mm}$, preoperatively. According to ANOVA analysis, there was a significant difference in proximal thoracic Cobb angle, main thoracic Cobb angle, thoracolumbar/lumbar Cobb angle, and thoracic AVT when comparing the preoperative $\mathrm{X}$-ray with immediate postoperative erect X-ray or in preoperative $\mathrm{X}$-ray and final follow-up X-ray. No significant difference was found in the parameters when comparing the immediate postoperative erect and final follow-up review $\mathrm{X}$-rays. With arthrodesis, the main thoracic curve's correction was approximately $30^{\circ}$ and remained stable until the final follow-up. The thoracolumbar/lumbar curve was spontaneously compensated with a correction rate of more than $70 \%$. The preoperative mean thoracic AVT was $33.0 \pm 9.1 \mathrm{~mm}$ and was significantly improved at immediate erect postoperatively $(P<0.001)$ and at final follow-up $(P<0.001)$. Additionally, no significant difference was observed in either lumbar AVT or coronal balance. 
Table 2

Radiographic parameters of recruited patients preoperatively, at immediate erect and at final follow-up.

\begin{tabular}{|c|c|c|c|c|c|c|}
\hline & Preoperatively & $\begin{array}{l}\text { Immediate } \\
\text { erect }\end{array}$ & $\begin{array}{l}\text { Final } \\
\text { follow- } \\
\text { up }\end{array}$ & $\begin{array}{l}\text { P value } \\
\text { (Pre vs. } \\
\text { Im) }\end{array}$ & $\begin{array}{l}\text { P value } \\
\text { (Pre vs. } \\
\text { Final) }\end{array}$ & $\begin{array}{l}\text { P value } \\
\text { (Im vs. } \\
\text { Final) }\end{array}$ \\
\hline $\begin{array}{l}\text { Proximal thoracic } \\
\text { curve }\end{array}$ & $27.2 \pm 13.3$ & $16.5 \pm 8.2$ & $\begin{array}{l}14.8 \pm \\
7.7\end{array}$ & $<0.001$ & $<0.001$ & 0.393 \\
\hline Main thoracic curve & $44.1 \pm 7.7$ & $13.6 \pm 7.8$ & $\begin{array}{l}13.8 \pm \\
8.0\end{array}$ & $<0.001$ & $<0.001$ & 0.886 \\
\hline Lumbar curve & $24.1 \pm 9.3$ & 8. $2 \pm 9.2$ & $\begin{array}{l}7.0 \pm \\
9.2\end{array}$ & $<0.001$ & $<0.001$ & 0.486 \\
\hline Thoracic AVT & $33.0 \pm 9.1$ & $12.7 \pm 6.8$ & $\begin{array}{l}14.0 \pm \\
7.3\end{array}$ & $<0.001$ & $<0.001$ & 0.398 \\
\hline Lumbar AVT & $13.9 \pm 7.1$ & $11.2 \pm 7.6$ & $\begin{array}{l}11.4 \pm \\
7.9\end{array}$ & 0.074 & 0.102 & 0.876 \\
\hline CB (C7PL-CSVL) & $11.2 \pm 7.9$ & $10.7 \pm 8.0$ & $\begin{array}{l}9.3 \pm \\
7.7\end{array}$ & 0.652 & 0.951 & 0.697 \\
\hline $\begin{array}{l}\mathrm{L} 1 / 2 \text { disc wedge } \\
\text { angle }\end{array}$ & $-2.86 \pm 4.32$ & $-0.16 \pm 3.89$ & $\begin{array}{l}0.98 \pm \\
4.80\end{array}$ & 0.002 & $<0.001$ & 0.189 \\
\hline $\begin{array}{l}\mathrm{L} 2 / 3 \text { disc wedge } \\
\text { angle }\end{array}$ & $-3.53 \pm 4.22$ & $-0.72 \pm 3.47$ & $\begin{array}{l}-0.45 \pm \\
3.16\end{array}$ & $<0.001$ & $<0.001$ & 0.706 \\
\hline $\begin{array}{l}\text { L3/4 disc wedge } \\
\text { angle }\end{array}$ & $-2.71 \pm 4.55$ & $-0.49 \pm 2.46$ & $\begin{array}{l}-0.41 \pm \\
3.16\end{array}$ & 0.002 & 0.001 & 0.904 \\
\hline $\begin{array}{l}\mathrm{L} 4 / 5 \text { disc wedge } \\
\text { angle }\end{array}$ & $-0.36 \pm 3.40$ & $-0.57 \pm 3.25$ & $\begin{array}{l}-0.48 \pm \\
2.78\end{array}$ & 0.735 & 0.843 & 0.888 \\
\hline $\begin{array}{l}\text { L5/S1 disc wedge } \\
\text { angle }\end{array}$ & $2.03 \pm 2.57$ & $1.44 \pm 3.12$ & $\begin{array}{l}0.67 \pm \\
2.29\end{array}$ & 0.269 & 0.011 & 0.147 \\
\hline $\begin{array}{l}\text { Upper coronal lumbar } \\
\text { curve }\end{array}$ & $15.87 \pm 6.64$ & $\begin{array}{l}10.33 \pm \\
5.71\end{array}$ & $\begin{array}{l}5.34 \pm \\
6.16\end{array}$ & $<0.001$ & $<0.001$ & 0.010 \\
\hline $\begin{array}{l}\text { Lower coronal lumbar } \\
\text { curve }\end{array}$ & $5.08 \pm 3.93$ & $5.15 \pm 3.70$ & $\begin{array}{l}4.46 \pm \\
3.79\end{array}$ & 0.917 & 0.276 & 0.433 \\
\hline
\end{tabular}


Table 3

Comparison of segmental and regional compensation at immediate erect and final follow-up.

compensation

$P$ value

\begin{tabular}{|c|c|c|c|c|c|c|c|c|c|c|}
\hline & $\mathrm{L} 1 / 2$ & $\mathrm{~L} 2 / 3$ & L3/4 & L4/5 & L5/S1 & $\begin{array}{l}\text { Overall } \\
\mathrm{P} \\
\text { value }\end{array}$ & $\mathrm{P} 1$ & $\mathrm{P} 2$ & P3 & P4 \\
\hline \multicolumn{11}{|c|}{ Disc parameters } \\
\hline $\begin{array}{l}\text { Immediate } \\
\text { erect minus } \\
\text { preoperative }\end{array}$ & $\begin{array}{l}2.70 \\
\pm \\
4.68\end{array}$ & $\begin{array}{l}2.82 \\
\pm \\
4.19\end{array}$ & $\begin{array}{l}2.21 \\
\pm \\
4.38\end{array}$ & $\begin{array}{l}-0.21 \\
\pm \\
4.31\end{array}$ & $\begin{array}{l}-0.59 \\
\pm 2.71\end{array}$ & $\hat{0} .001$ & 0.889 & 0.461 & 0.003 & 0.643 \\
\hline $\begin{array}{l}\text { Final follow- } \\
\text { up minus } \\
\text { preoperative }\end{array}$ & $\begin{array}{l}3.84 \\
\pm \\
5.96\end{array}$ & $\begin{array}{l}3.09 \\
\pm \\
4.54\end{array}$ & $\begin{array}{l}2.30 \\
\pm \\
4.53\end{array}$ & $\begin{array}{l}-0.12 \\
\pm \\
3.89\end{array}$ & $\begin{array}{l}-1.36 \\
\pm 2.80\end{array}$ & <. 001 & 0.396 & 0.372 & 0.007 & 0.162 \\
\hline$P$ value & 0.286 & 0.753 & 0.718 & 0.924 & 0.159 & -- & & & & \\
\hline \multirow{2}{*}{$\begin{array}{l}\text { Lumbar } \\
\text { curve }\end{array}$} & \multicolumn{5}{|c|}{ compensation } & \multicolumn{3}{|c|}{ paired $t$ test } & & \\
\hline & \multicolumn{3}{|c|}{$\begin{array}{l}\text { Upper coronal lumbar } \\
\text { curve }\end{array}$} & \multicolumn{2}{|c|}{$\begin{array}{l}\text { Lower coronal } \\
\text { lumbar curve }\end{array}$} & \multicolumn{2}{|c|}{$P$ value } & & & \\
\hline $\begin{array}{l}\text { Immediate } \\
\text { erect minus } \\
\text { preoperative }\end{array}$ & \multicolumn{3}{|c|}{$7.73 \pm 8.85$} & \multicolumn{2}{|c|}{$-0.80 \pm 5.13$} & \multicolumn{2}{|c|}{$<0.001$} & & & \\
\hline $\begin{array}{l}\text { Final follow- } \\
\text { up minus } \\
\text { preoperative }\end{array}$ & \multicolumn{3}{|c|}{$9.22 \pm 10.39$} & \multicolumn{2}{|c|}{$-1.49 \pm 5.14$} & \multicolumn{2}{|c|}{$<0.001$} & & & \\
\hline
\end{tabular}

Table 4

Correlation between each disc wedge angle and lumbar Cobb angle preoperatively and at final follow-up.

\begin{tabular}{|llllll|}
\hline $\begin{array}{l}\text { Preoperative } \\
\text { disc wedge } \\
\text { angle }\end{array}$ & \multicolumn{2}{l}{$\begin{array}{l}\text { Preoperative Lumbar Cobb } \\
\text { angle }\end{array}$} & $\begin{array}{l}\text { Disc wedge } \\
\text { angle }\end{array}$ & \multicolumn{2}{l|}{$\begin{array}{l}\text { Lumbar Cobb angle at final } \\
\text { follow-up }\end{array}$} \\
\cline { 2 - 3 } & Correlation & P value & $\begin{array}{l}\text { at final follow- } \\
\text { up }\end{array}$ & Correlation & P value \\
\hline L1/2 & 0.557 & $<0.001$ & L1/2 & 0.518 & $<0.001$ \\
\hline L2/3 & 0.450 & $<0.001$ & L2/3 & 0.468 & 0.001 \\
\hline L3/4 & 0.205 & 0.148 & L3/4 & 0.201 & 0.158 \\
\hline L4/5 & 0.364 & 0.009 & L4/5 & 0.067 & 0.640 \\
\hline L5/S1 & -0.289 & 0.040 & L5/S1 & -0.149 & 0.298 \\
\hline
\end{tabular}

The preoperative disc wedge angles of $\mathrm{L} 1 / 2, \mathrm{~L} 2 / 3, \mathrm{~L} 3 / 4, \mathrm{~L} 4 / 5$ and $\mathrm{L} 5 / \mathrm{S} 1$ were $-2.86 \pm 4.32^{\circ},-3.53 \pm 4.22^{\circ}$, $-2.71 \pm 4.55^{\circ},-0.36 \pm 3.40^{\circ}$ and $2.03 \pm 2.57^{\circ}$, respectively. At the final follow-up, the disc wedge angle was approximately zero with spontaneous correction of the lumbar curve. However, as for L4/5 disc and L5/S1 
disc level, a significant difference between preoperative and postoperative immediate $\mathrm{X}$-rays was detected in each distal unfused disc wedge angle. A significant difference was found at final follow-up in L1/2 disc, L2/3 disc, L3/4 disc, and L5/S1 disc level compared to preoperative X-ray. When considered upper and lower coronal lumbar curve as integral, the upper integral showed significance whether in the postoperative period or at final follow-up. The preoperative upper and lower coronal lumbar curve were $15.87 \pm 6.64^{\circ}$ and $5.08 \pm$ $3.93^{\circ}$, which were changed to $10.33 \pm 5.71^{\circ}$ and $5.15 \pm 3.70^{\circ}$ immediately after surgery. At the final follow-up, the results turned to $5.34 \pm 6.16^{\circ}$ and $4.46 \pm 3.79^{\circ}$, respectively.

The disc wedge angle variation was calculated to investigate further how each disc level changed and whether this variation was consistent. Immediate disc wedge angle variation was $2.70 \pm 4.68^{\circ}, 2.82 \pm 4.19^{\circ}$, $2.21 \pm 4.38^{\circ},-0.21 \pm 4.31^{\circ}$ and $-0.59 \pm 2.71^{\circ}$, respectively. The disc wedge angle variation at final follow-up was $3.84 \pm 5.96^{\circ}, 3.09 \pm 4.54^{\circ}, 2.30 \pm 4.53^{\circ},-0.12 \pm 3.89^{\circ}$ and $-1.36 \pm 2.80^{\circ}$, respectively. Significant differences were found in disc wedge angle variation among each segment after treatment, whether at immediate erect postoperatively or final follow-up. Pairwise comparison showed further significance between $\mathrm{L} 3 / 4$ and $\mathrm{L} 4 / 5$ level postoperatively. As shown in Fig. 2, each disc wedge angle variation presented a decreasing tendency: the further lower the spine, there is the less likely difference. The L1/2 disc and L2/3 disc contributed the most to the lumbar compensation. Besides, by calculating the integral compensation of upper and lower parts, we found the upper coronal lumbar curve play a more significant role of distal unfused lumbar compensation whether in the postoperative period $\left(7.73 \pm 8.85^{\circ} \mathrm{vs}-0.80 \pm 5.13^{\circ}, \mathrm{P}<0.001\right)$ or at final follow-up $\left(9.22 \pm 10.39^{\circ}\right.$ vs $\left.-1.49 \pm 5.14^{\circ}, P<0.001\right)$. Furthermore, the total disc compensation was added by distal un-instrumented disc wedge angle variation. This compensation accounts for $43.6 \%$ at immediate erect and $45.0 \%$ at final follow-up.

As shown in Table. 4, a strong association was found between the following disc wedge angle and the TL/L Cobb angle at final follow-up using Pearson correlation statistics: L1/2 wedge angle $(r=0.518, p<0.001)$ and L2/3 wedge angle $(r=0.468, p=0.001)$. Moreover, the correlation of disc compensation and spontaneous lumbar correction at final follow-up showed a similar tendency (Table 5): $L 1 / 2$ disc compensation $(r=0.542$, $p<0.001)$ and $L 2 / 3$ disc compensation $(r=0.437, p=0.001)$. As for the preoperative $T L / L$ Cobb angle, the correlation was not significant in the preoperative $L 3 / 4$ wedge angle $(r=0.205, p=0.148)$. 
Table 5

Correlation between each lumbar segment compensation and total lumbar compensation at final follow-up.

\begin{tabular}{|lll|}
\hline Disc compensation & \multicolumn{2}{l|}{ Total lumbar compensation } \\
\cline { 2 - 3 } & Correlation & P value \\
\hline L1/2 & 0.542 & $<0.001$ \\
\hline L2/3 & 0.437 & 0.001 \\
\hline L3/4 & 0.087 & 0.544 \\
\hline L4/5 & 0.080 & 0.579 \\
\hline L5/S1 & -0.266 & 0.060 \\
\hline
\end{tabular}

\section{Discussion}

Previously many studies have been conducted on the compensation of lumbar curvature after the selective thoracic fusion. Koller et al. (K. H et al., 2019) proposed an accurate prediction model for postoperative SLCC based on the analysis of many prospective STF cases. Danilo et al. (D \& AO, 2016) conducted a retrospective cohort study of 42 Lenke 1 AIS patients and concluded that the main thoracic curve's overcorrection might result in less satisfactory results. Matthew et al. (MB et al., 2004) indicated that the preoperative push-prone is the best preoperative flexibility radiograph to predict the final lumbar curve measurement. Pasha et al. (P. S \& JM, 2019) then developed a decision tree to define criteria for optimal lumbar curve correction following STF in Lenke 1 AIS. Schulz et al. (Schulz et al., 2014) pointed out that optimal postoperative outcomes for STF should include a lumbar Cobb angle less than $26^{\circ}$, coronal balance $2 \mathrm{~cm}$ or less, deformity-flexibility quotient less than 4 , lumbar correction more than $37 \%$, and trunk shift less than $1.5 \mathrm{~cm}$. However, these studies only focus on overall compensation behavior and aim to improve clinical strategies.

In this study, we calculated each disc wedge variation of distal unfused lumbar segments to further elucidate the characteristics of spontaneous compensation of the lumbar curve after STF. The results showed that the proximal two segments at level $L 1 / 2$ and $L 2 / 3$ accounted for most total compensation. The distal unfused lumbar segments provided the more distal the segment, the less compensation. Furthermore, we found that total disc compensation consisted of less than half of the total postoperative lumbar curve compensation. This phenomenon may indicate that the lumbar curvature is often affected and includes the thoracic vertebrae, such as T10, T11 and T12. However, since all of our cases chose L1 as LIV, our study did not further investigate the fused thoracic discs, we focused attention on the unfused lumbar segments. As shown in Fig. 2, the compensation ability of the lumbar segments showed a decreasing tendency, with a major role being played by the proximal adjacent lumbar curve. Moreover, our integral analysis indicated that the upper coronal lumbar curve was responsible for most of the compensation, which was consistent with the opinion of $\mathrm{Na}$ et al. ( $\mathrm{Na}, \mathrm{Ha}, \mathrm{Harms}, \&$ Choi, 2010). They were the first to divide the lumbar curve into the proximal and distal curves by their respective lumbar apex and concluded that looking at the proximal lumbar curve flexibility might be an alternative indicator for measuring the lumbar flexibility in MT-AIS 
patients treated by STF. We believe that the characteristics of residual lumbar curve after STF may be closely associated with the adding-on phenomenon and may provide evidence when choosing the correct LIV.

Then, what is the reason for the non-uniformity of unfused distal segment compensation? We believed that the flexibility of the distal unfused segments might be different. Zhao et al. (J et al., 2018) analyzed the characteristics of cobb angle distribution in the Lenke $5 \mathrm{C}$ AlS patients. They found that the disc angles had symmetric distribution in the main thoracolumbar/lumbar curve, while the distal segment is more flexible. The thoracolumbar/lumbar curve's apex was often L1 or L2 vertebrae, and its distal segments may correspond to the L1/2 and L2/3 segments that were consistent with our study results. Na et al. (Na et al., 2010) also found that the lumbar apex of 28 main thoracic curve patients was between L2 and L3, and concluded that the curve flexibility of the proximal lumbar area could be meaningful. Jansen et al. (RC, LW, E, \& A, 2007) also concluded that in STF patients, the most correction was made in the upper part of the lumbar curve, while the distal lumbar curve seemed to be more rigid and less important in spontaneous curve correction. In addition, another reasonable hypothesis may be the mechanical effect of posterior fusion with the pedicle screw. This phenomenon was similar to complications on the sagittal plane, such as PJK(HJ et al., 2020; O. S et al., 2019) and DJK(P, M, M, F, \& C, 2020), which we believed could result from stress concentration on the adjacent segments. Meric et al. (Enercan et al., 2015) have shown that facet joint degeneration is significant at the upper two levels adjacent to the LIV when performing STF. Furthermore, this may be explained by the principle of load-sharing, that when arthrodesis was applied, the posterior fixation conducted most of the forces to the lowest instrumented vertebrae. Furthermore, when this force is overloaded, the stress could be conducted to the most adjacent segments. This has related to coronal complications, which could lead to complications, including adding-on phenomenon and coronal imbalance.

Therefore, when planning surgical treatment strategies, the characteristics of unfused lumbar segments should be carefully considered. Inappropriate curve selection and excessive thoracic correction have been identified as the most common etiologies of coronal imbalance(J. H et al., 2018; W et al., 2018; $Y$ et al., 2019). Meanwhile, numerous studies(MA \& DM, 2011; Skaggs et al., 2016; $W$ et al., 2018; $X$ et al., 2016; $Y$ et al., 2019) have demonstrated improper placement of the LIV is also an independent risk factor. It is also important to realize the heterogeneity of spontaneous compensation of unfused lumbar segments. When selectively fusing the thoracic curvature, the overall compensation ability of the lumbar curvature and the heterogeneity of compensation to avoid excessive compensation at the proximal end should be considered.

Even though our study focused on the residual lumbar curve segmental characteristics in Lenke 1 and 2 AIS patients who were performed STF, several limitations should be considered. First, we only included patients whose LIV was L1 vertebrae for the homogeneity analysis of disc compensation. Further researches on other LIV selection and comparison should be performed. Second, only coronal position data were studied in our research but not a sagittal plane, and there was no specific analysis of related complications. Finally, this was a single-center study, and multi-centric research should be conducted to further validate the results.

\section{Conclusion}

The residual lumbar curve can be corrected spontaneously with the thoracic curve correction after posterior selective thoracic fusion in Lenke 1 and 2 AlS patients. When selecting L1 as the lowest instrumented 
vertebrae, the compensation of distal unfused lumbar segments showed a declining tendency to contribute to the compensation; with the immediately adjacent $\mathrm{L} 1 / 2$ and $\mathrm{L} 2 / 3$ disc contributed most in this compensation.

\section{Abbreviations}

AIS: adolescent idiopathic scoliosis

STF: selective thoracic fusion

SLCC: spontaneous lumbar curve correction

LIV: lowest instrumented vertebrae

UIV: upper instrumented vertebrae

TAVT: translation of thoracic apex

C7PL: the cervical 7 vertebrae plumb line

LAVT: translation of thoracolumbar/lumbar apex

CSVL: the center sacral vertical line

SD: standard deviation

\section{Declarations}

\section{Availability of data and materials}

The data that support the findings of this study are available from Changhai Hospital, China but restrictions apply to the availability of these data, which were used under license for the current study, and so are not publicly available. Data are however available from the authors upon reasonable request and with permission of Changhai Hospital, China.

\section{Ethical Approval}

This study was approved by the ethics committee of our university (Local Ethics Committee of Changhai Hospital, SMMU, No. CHEC20170163). And all subjects in our study provided written informed consent for the study.

\section{Consent for publication (Not applicable)}

I, Kai Chen give my consent for information about myself to be published in BMC Musculoskeletal Disorders and Ming Li. I understand that the information will be published without my name attached, but that full anonymity cannot be guaranteed. I understand that the text and any pictures or videos published in the 
article will be freely available on the internet and may be seen by the general public. The pictures, videos and text may also appear on other websites or in print, may be translated into other languages or used for commercial purposes. I have been offered the opportunity to read the manuscript. Signing this consent form does not remove my rights to privacy.

\section{Competing interests}

The author(s) declared no potential conflicts of interest with respect to the research, authorship, and/or publication of this article.

\section{Funding}

This study was supported by National Natural Science Fund of China (namely Nos.81972035).

\section{Authors' contributions}

Kai Chen, Xiao Zhai, Tianjunke Zhou, Yu Deng contributed equally to this paper, and were the Co-first author.

\section{Acknowledgement}

We sincerely thank all the patients and individuals for their participation and all the researcher for contribution to this article.

\section{Publisher's Note}

Springer Nature remains neutral with regard to jurisdictional claims in published maps and institutional affiliations.

\section{References}

1. Bachmann, K. R., Lu, E., Novicoff, W. M., Newton, P. O., Abel, M. F., Buckland, A., . . Upasani, V. (2020). The Lumbosacral Takeoff Angle Can Be Used to Predict the Postoperative Lumbar Cobb Angle Following Selective Thoracic Fusion in Patients with Adolescent Idiopathic Scoliosis. J Bone Joint Surg Am, 102(2), 143-150. http://doi.org/10.2106/jbjs.19.00287

2. Betz, R. R. (2016). Should All AIS 1C Curves Be Fused Selectively? Spine (Phila Pa 1976), 41 Suppl 7, S16-17. http://doi.org/10.1097/brs.0000000000001427

3. Chang, K. W., Chang, K. I., \& Wu, C. M. (2007). Enhanced capacity for spontaneous correction of lumbar curve in the treatment of major thoracic-compensatory $\mathrm{C}$ modifier lumbar curve pattern in idiopathic scoliosis. Spine (Phila Pa 1976), 32(26), 3020-3029. http://doi.org/10.1097/BRS.0b013e31815cdde3

4. D, M., \& AO, G. (2016). Assessment of spontaneous correction of lumbar curve after fusion of the main thoracic in Lenke 1 adolescent idiopathic scoliosis. Revista brasileira de ortopedia, 51(1), 83-89. http://doi.org/10.1016/j.rboe.2015.03.013

5. DE, M., \& P, C. (1991). Spinal decompensation in Cotrel-Dubousset instrumentation. Spine, 16, S394-403. 
6. Enercan, M., Kahraman, S., Cobanoglu, M., Yilar, S., Gokcen, B. H., Karadereler, S., .. . Hamzaoglu, A. (2015). Selective Thoracic Fusion Provides Similar Health-Related Quality of Life but Can Cause More Lumbar Disc and Facet Joint Degeneration: A Comparison of Adolescent Idiopathic Scoliosis Patients With Normal Population 10 Years After Surgery. Spine Deform, 3(5), 469-475.

http://doi.org/10.1016/j.jspd.2015.07.001

7. H, J., W, S., E, X., Z, J., T, L., Y, M., . . X X Z. (2018). Coronal Imbalance after Selective Posterior Thoracic Fusion in Patients with Lenke 1 and 2 Adolescent Idiopathic Scoliosis. BioMed research international, 2018, 3476425. http://doi.org/10.1155/2018/3476425

8. H, K., W, H., MC, M., \& PO, N. (2019). Accurate prediction of spontaneous lumbar curve correction following posterior selective thoracic fusion in adolescent idiopathic scoliosis using logistic regression models and clinical rationale. European spine journal : official publication of the European Spine Society, the European Spinal Deformity Society, and the European Section of the Cervical Spine Research Society, 28(9), 1987-1997. http://doi.org/10.1007/s00586-019-06000-6

9. HJ, K., SJ, W., R, L., S, I., C, S., G, M., . . V, L. (2020). Recurrent Proximal Junctional Kyphosis: Incidence, Risk Factors, Revision Rates, and Outcomes at 2-Year Minimum Follow-up. Spine, 45(1), E18-E24. http://doi.org/10.1097/brs.0000000000003202

10. J, Z., J, F., H, S., C, Y., Y, C., \& M, L. (2018). Characteristics of Cobb angle distribution in the main thoracolumbar/lumbar curve in adolescent idiopathic scoliosis: A retrospective controlled clinical study. Medicine, 97(25), e11216. http://doi.org/10.1097/md.0000000000011216

11. KH, N., J, H., KY, H., \& NY, C. (2007). Sagittal plane lumbar responses after anterior selective thoracic fusion for main thoracic adolescent idiopathic scoliosis. Asian Spine J, 1(2), 80-87. http://doi.org/10.4184/asj.2007.1.2.80

12. Koller, H., Meier, O., Albrecht, H., Schmidt, R., Zenner, J., \& Hitzl, W. (2014). Selective thoracic fusion in AIS curves: the definition of target outcomes improves the prediction of spontaneous lumbar curve correction (SLCC). Eur Spine J, 23(6), 1263-1281. http://doi.org/10.1007/s00586-014-3280-4

13. Lenke, L. G., Betz, R. R., Bridwell, K. H., Harms, J., Clements, D. H., \& Lowe, T. G. (1999). Spontaneous lumbar curve coronal correction after selective anterior or posterior thoracic fusion in adolescent idiopathic scoliosis. Spine (Phila Pa 1976), 24(16), 1663-1671; discussion 1672. http://doi.org/10.1097/00007632-199908150-00007

14. LG, L. (2007). The Lenke classification system of operative adolescent idiopathic scoliosis. Neurosurgery clinics of North America, 18(2), 199-206. http://doi.org/10.1016/j.nec.2007.02.006

15. M, I., M, N., \& M, K. (2019). Selective Thoracic Fusion for King-Moe Type II/Lenke 1C Curve in Adolescent Idiopathic Scoliosis: A Comprehensive Review of Major Concerns. Spine surgery and related research, 3(2), 113-125. http://doi.org/10.22603/ssrr.2018-0047

16. M, U., J, T., S, I., S, K., T, F., H, O., . . H, K. (2019). Prediction of Spontaneous Lumbar Curve Correction After Posterior Spinal Fusion for Adolescent Idiopathic Scoliosis Lenke Type 1 Curves. Clinical spine surgery, 32(2), E112-E116. http://doi.org/10.1097/bsd.0000000000000736

17. MA, E., \& DM, B. (2011). Lowest instrumented vertebra selection in AIS. Journal of pediatric orthopedics, 31, S69-76. http://doi.org/10.1097/BPO.0b013e318202bfcd 
18. MB, D., LG, L., T, W., M, P., G, D. R., K, S.-M., \& KH, B. (2004). Can we predict the ultimate lumbar curve in adolescent idiopathic scoliosis patients undergoing a selective fusion with undercorrection of the thoracic curve? Spine, 29(3), 277-285. http://doi.org/10.1097/01.brs.0000106488.51299.75

19. MK, K., CK, C., PH, T., XH, C., XY, L., YH, N., . . CYW, C. (2018). Radiological and clinical outcome of selective thoracic fusion for patients with Lenke $1 \mathrm{C}$ and $2 \mathrm{C}$ adolescent idiopathic scoliosis with a minimum follow-up of 2 years. The spine journal : official journal of the North American Spine Society, 18(12), 2239-2246. http://doi.org/10.1016/j.spinee.2018.05.007

20. Na, K. H., Ha, K. Y., Harms, J., \& Choi, N. Y. (2010). The efficacy of proximal lumbar curve flexibility in patients with main thoracic adolescent idiopathic scoliosis treated by selective thoracic fusion surgery. Asian Spine J, 4(1), 32-38. http://doi.org/10.4184/asj.2010.4.1.32

21. Nohara, A., Kawakami, N., Saito, T., Tsuji, T., Ohara, T., Suzuki, Y., . . Kawakami, K. (2015). Comparison of Surgical Outcomes Between Anterior Fusion and Posterior Fusion in Patients With AIS Lenke Type 1 or 2 that Underwent Selective Thoracic Fusion -Long-term Follow-up Study Longer Than 10 Postoperative Years. Spine (Phila Pa 1976), 40(21), 1681-1689. http://doi.org/10.1097/brs.0000000000001121

22. P, B., M, D., M, P., F, L., \& C, L. (2020). Revision surgery in distal junctional kyphosis. European spine journal : official publication of the European Spine Society, the European Spinal Deformity Society, and the European Section of the Cervical Spine Research Society, 29, 86-102. http://doi.org/10.1007/s00586020-06304-y

23. RC, J., LW, v. R., E, D., \& A, v. O. (2007). Predictability of the spontaneous lumbar curve correction after selective thoracic fusion in idiopathic scoliosis. European spine journal : official publication of the European Spine Society, the European Spinal Deformity Society, and the European Section of the Cervical Spine Research Society, 16(9), 1335-1342. http://doi.org/10.1007/s00586-007-0320-3

24. S, O., D, T., T, H., Y, Y., G, Y., S, K., . . Y, M. (2019). The Risk of Proximal Junctional Kyphosis Decreases in Patients With Optimal Thoracic Kyphosis. Spine deformity, 7(5), 759-770. http://doi.org/10.1016/j.jspd.2018.12.007

25. S, P., \& JM, M.-T. (2019). Defining criteria for optimal lumbar curve correction following the selective thoracic fusion surgery in Lenke 1 adolescent idiopathic scoliosis: developing a decision tree. European journal of orthopaedic surgery \& traumatology : orthopedie traumatologie. http://doi.org/10.1007/s00590-019-02596-z

26. Schulz, J., Asghar, J., Bastrom, T., Shufflebarger, H., Newton, P. O., Sturm, P., . . Yaszay, B. (2014). Optimal radiographical criteria after selective thoracic fusion for patients with adolescent idiopathic scoliosis with a C lumbar modifier: does adherence to current guidelines predict success? Spine (Phila Pa 1976), 39(23), E1368-1373. http://doi.org/10.1097/brs.0000000000000580

27. Skaggs, D. L., Seehausen, D. A., Yamaguchi, K. T., Jr., Hah, R. J., Wright, M. L., Bumpass, D. B., . . Lenke, L. G. (2016). Assessment of Lowest Instrumented Vertebra Tilt on Radiographic Measurements in Lenke "C" Modifier Curves Undergoing Selective Thoracic Fusion in Adolescent Idiopathic Scoliosis. Spine Deform, 4(2), 125-130. http://doi.org/10.1016/j.jspd.2015.08.006

28. Sudo, H. S., Mayer, M. M., Kaneda, K. K., Nunez-Pereira, S., Shono, S. Y., Hitzl, W. H., . . Koller, H. K. (2016). Maintenance of spontaneous lumbar curve correction following thoracic fusion of main thoracic 
curves in adolescent idiopathic scoliosis. Bone Joint J, 98-b(7), 997-1002. http://doi.org/10.1302/0301$620 \times .98 b 7.37587$

29. TR, K., LG, L., DS, W., EJ, G., FA, S., RR, B., . . KM, B. (2001). Spontaneous proximal thoracic curve correction after isolated fusion of the main thoracic curve in adolescent idiopathic scoliosis. Spine, 26(18), 1966-1975. http://doi.org/10.1097/00007632-200109150-00006

30. U, L., H, H., \& V, B. (2013). Spontaneous lumbar curve correction in selective anterior instrumentation and fusion of idiopathic thoracic scoliosis of Lenke type C. European spine journal : official publication of the European Spine Society, the European Spinal Deformity Society, and the European Section of the Cervical Spine Research Society, S138-148. http://doi.org/10.1007/s00586-012-2299-7

31. W, C., MJ, F., D, E., G, S., T, R., M, C., \& O, B.-A. (2018). Additional Risk Factors for Adding-On After Selective Thoracic Fusion in Adolescent Idiopathic Scoliosis: Implication of Lowest Instrumented Vertebra Angle and Lumbosacral Takeoff. Spine deformity, 6(2), 164-169. http://doi.org/10.1016/j.jspd.2017.08.008

32. X, Q., W, S., L, X., Z, L., Y, Q., \& Z, Z. (2016). Selecting the Last "Substantially" Touching Vertebra as Lowest Instrumented Vertebra in Lenke Type 1A Curve: Radiographic Outcomes With a Minimum of 2year Follow-Up. Spine, 41(12), E742-750. http://doi.org/10.1097/brs.0000000000001374

33. Y, L., H, B., C, L., Y, Z., Y, F., T, L., . . Z Z, W. (2019). Distal Adding-On Phenomenon in Lenke IA and Lenke IIA: Risk Analysis and Selection of the Lowest Instrumented Vertebra. World neurosurgery. http://doi.org/10.1016/j.wneu.2019.12.087

\section{Figures}




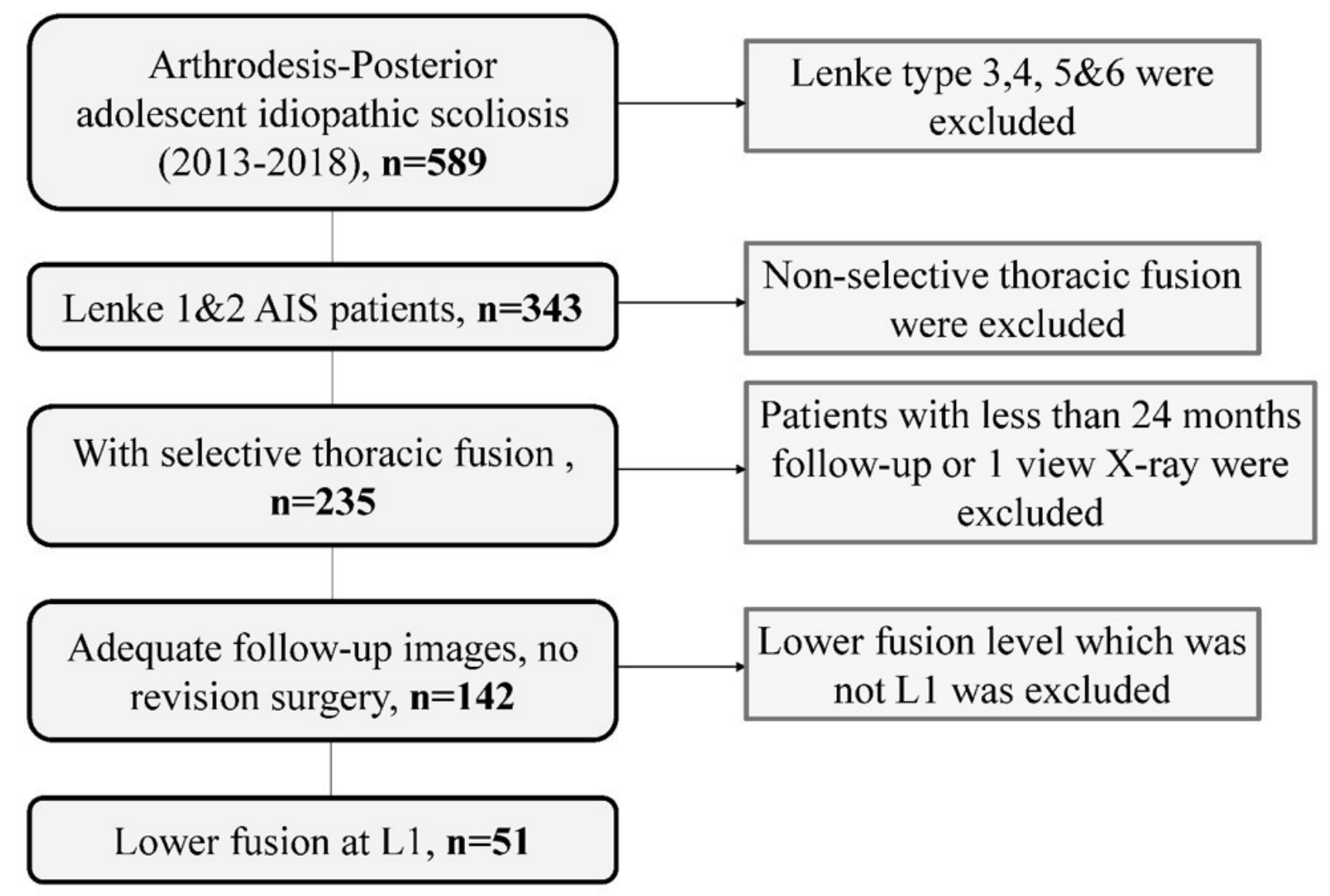

Figure 1

The disc wedge angle was measured as the angle between the lines along the inferior endplate of the upper and the superior endplate of the lower vertebra in a segment, $L 1 / 2, L 2 / 3, L 3 / 4, L 4 / 5$ and $L 5 / S 1$ disc were measured, respectively 


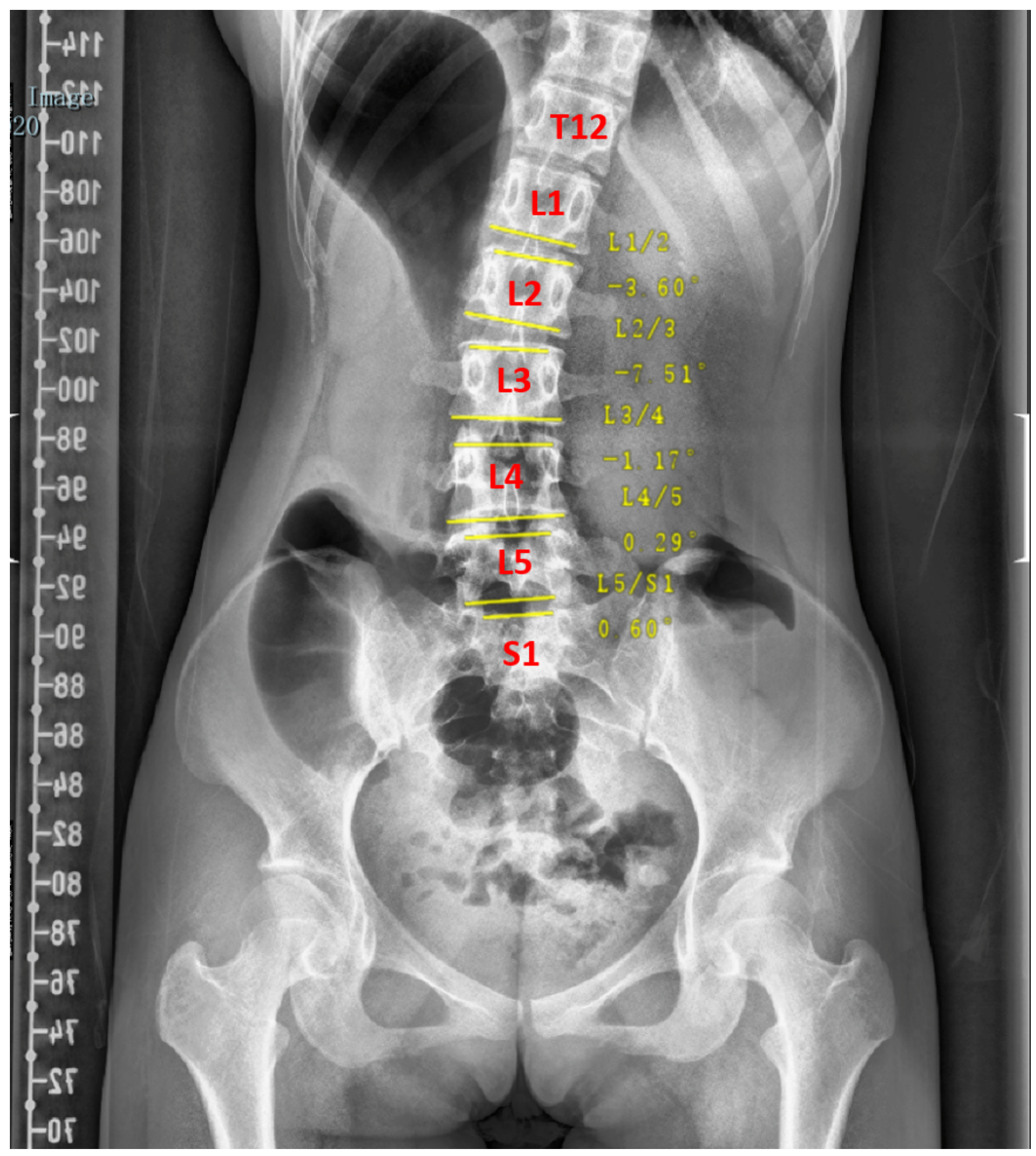

Figure 2

Significant differences were found in disc wedge angle variation among each segment after treatment, whether at immediate erect postoperatively or final follow-up. Pairwise comparison showed further significance between L3/4 and L4/5 level postoperatively 


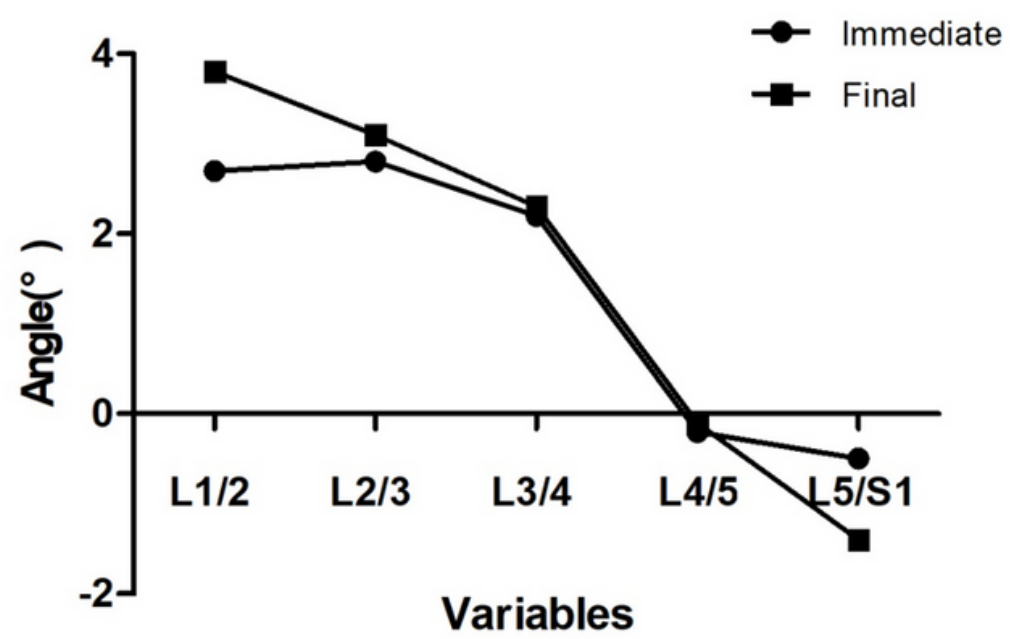

a

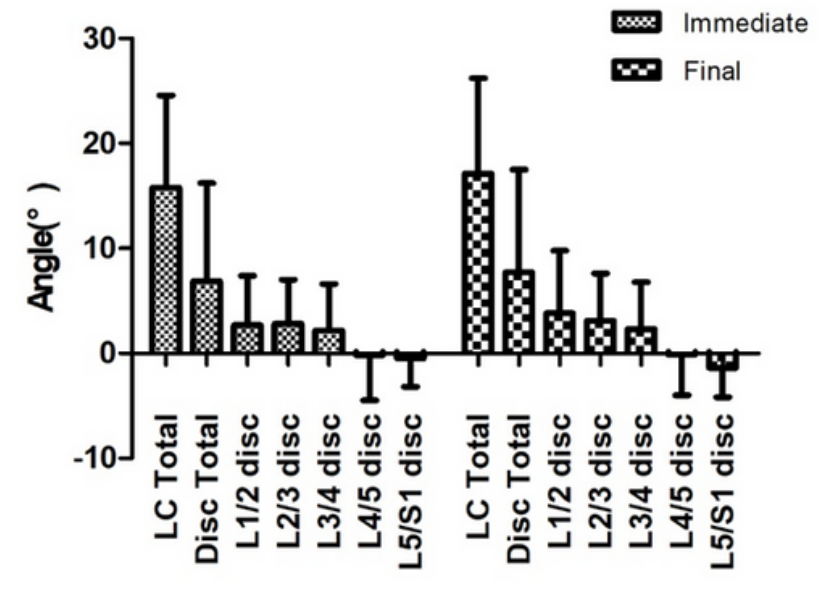

Variables

b

\section{Figure 3}

Significant differences were found in disc wedge angle variation among each segment after treatment, whether at immediate erect postoperatively or final follow-up. Pairwise comparison showed further significance between $L 3 / 4$ and $L 4 / 5$ level postoperatively 